\title{
RECORDED LINES FROM "AMERICA": A NEW POETIC ANALYSIS
}

\author{
CRISMAN COOLEY
}

AT THE END OF a 1992 article in the Walt Whitman Quarterly Review, entitled "Walt Whitman's Voice," Larry Don Griffin mentions the existence of a recording of Whitman reciting the first four lines from his 1888 poem "America." In the subsequent issue of $W W Q R$, Ed Folsom discusses whether this is indeed a recording of Walt Whitman. ${ }^{2}$ Since then, there has been an ongoing controversy over the authenticity of this recording. ${ }^{3}$ I want to return to this recording and listen to it carefully again, not to determine authenticity but rather to employ a musical approach to poetics that will help us see what the recording might mean in the context of Whitman's prosody. ${ }^{4}$

In my analysis of the recording, I will be ignoring timbre and focusing instead on the other three characteristics of sound evident in the recorded voice: duration, pitch, and dynamics. Unfortunately, the noise of the wax cylinder drowns out sound at pianissimo ( $p p$ ) making it impossible to hear the speaker breathe. If we could hear inhalation, we could discover whether or not breath in the recording is in fact a marker of line breaks.

Following is a musical transcription of the recording. This transcription will be the basis of my musical analysis of the recording. Those interested in the details of my methodology can read about it elsewhere. ${ }^{5}$ It is sufficient to indicate here that I used music editing software to load an .MP3 file of the recording of "America" into random access memory, and the complex representation of the recording in a digital sound wave (about thirty-five seconds in length) became the basis of the analysis. The notation follows practices for contemporary music. The staff has been stripped down to a single line without bar lines or meter to show that it is for the speaking voice, not for musical singing. This communicates that pitches will not be held (one defining difference between singing and everyday speech is that it is normal to hold a single pitch in singing, whereas, in everyday English speech, sustaining a note is extremely rare and unusual). In speech, "pitch" glides up and down freely, almost never remaining constant. An approximation of the pitch variation is transcribed using symbols for glissando and portamento- to capture large and small pitch variations (fig. 1). 
One reason for producing a musical transcription of a poetic text is that it provides details of the prosody unavailable through any other approach. Whitman was the most prominent early exponent of vers libre in the United States; his lines were also influenced by the King James Bible. ${ }^{6}$ His metrical innovations have had considerable influence on the poetry that has followed him in the United States. In casual terms, formal verse may be rhymed and rhythmically patterned, blank verse unrhymed and rhythmically patterned, and free verse unrhymed and rhythmically unpatterned-or more commonly, "non-metrical." But is free verse really "unpatterned"? Is it really "non-metrical"? If there are patterns, what are they? What is the relationship between rhythm and pitch? Or, more specifically, between accent and pitch? How is intonation related to the phrase? What are the relations between dynamics and accent? Or between dynamics and the phrase? We will briefly explore some of these questions with recourse to the transcription.

It is immediately evident that the speaker's recitation is not unpatterned. The word "America," for example, is broken into four syllables, each taking precisely 0.25 seconds-what appear as eighth notes at the tempo of 120 quarter notes per minute. That is a pattern, however brief. Pitch of the word rises, then falls. Dynamics rise, then fall. All the tracked attributes of sound exhibit parallel patterning in this first word.

The first phrase ends with two triplet figures: "equal daughters" and "equal sons." These figures belong together. Each of the first three syllables of the parallel figures has duration of very nearly one-third of a second (three quarter notes over two beats, equal to one second). Like a musical motif, the figure repeats at two different pitch levels, a descending pattern, and two dynamic levels, again descending in parallel. This is an interesting manifestation of the content plane (equality) on the expression plane.

There's one quite arresting fact evident in this first phrase: the speaker goes up in pitch on some unaccented syllables. This is extremely unusual, because there is a very high correlation between syllabic accent and pitch in all spoken English. In the first phrase, three out of four two-syllable words rise in pitch on the unaccented syllable: "centre" and both occurrences of "equal." In one previous study of a contemporary free verse poet, the accented syllable in a word received a higher pitch more than $99 \%$ of the time. ${ }^{7}$ Whether this is characteristic of a dialect of English from another time and place, a personal idiosyncrasy, or a poetic affectation of the reader is difficult to say.

The first phrase is a combination of eighth notes ( 0.25 seconds each) and triplet quarter notes ( 0.33 seconds each). The regularity of these in relation to the implied pulse of the tempo (120 quarter notes per minute) is complicated, however, by the spacing between the figures. After the word "daughters" and before the words "equal sons," there is a pause 


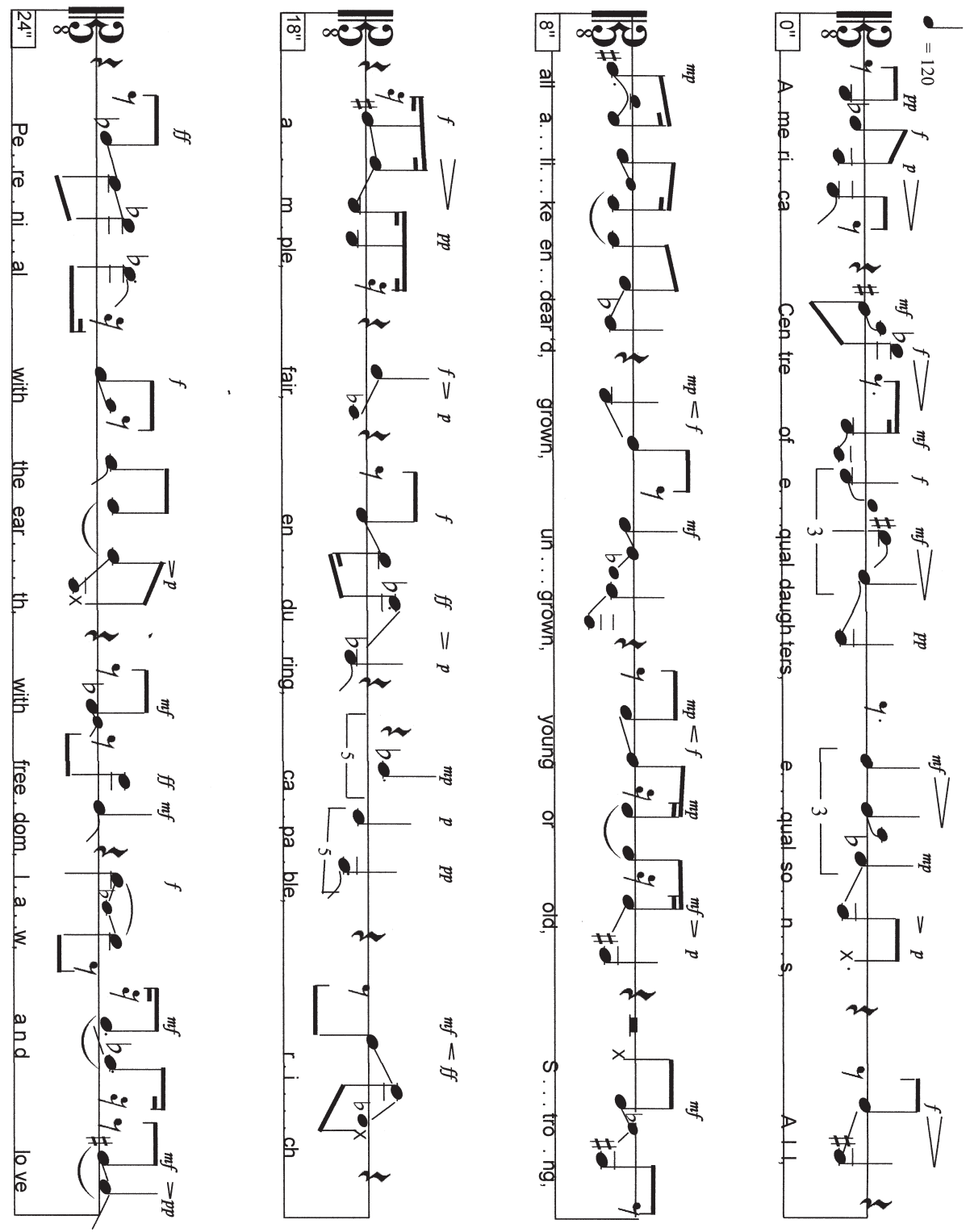

Figure 1 
of 0.375 seconds, notated as a dotted eighth rest. This makes the music rather complex at this point, and the complexity, a kind of syncopation, doesn't end until the final "s" in "sons," which is a dotted eighth note. Of course, it isn't really syncopation at all. It is evident from this that the speaker is not feeling any pulse and therefore does not pause at an interval regular to the underlying tempo. Yet, despite this lack of an explicit recognition of pulse, it is remarkable how many of the syllables in the poem are measured quite precisely in eighth notes at an unvarying tempo of 120 quarter notes per minute.

We can hear the first phrase as musically satisfying because of the way the intonation rises from the G2 (first syllable of "America") up to $\mathrm{Ab}$ (second syllable of "centre"), then falling to the F2 at the final phoneme of "sons." The dynamics follow a similar rising and falling pattern.

The timing and force of the word "All" that begins the second phrase is surprising, even shocking. It strikes my ear as syncopation-as the transcription bears out. The dynamic level is forte $(f)$. And the way the speaker allows the word to hang in silence for a moment (a quarter rest following it), and to sink from the $\mathrm{C}$ to $\mathrm{F} \#$ below, as if it were a complete statement in itself, adds to the drama. Close listening reveals an authority of enunciation throughout. The assuredness packed into the rhythmic surprise and intonation of this word (the first time) indicates a mastery and complete integration by the speaker of the text. This kind of integration is quite rare. It is most commonly heard either in unpremeditated speech on the street or in the work of an excellent actor.

The expression plane of the second phrase contains further content manifest on it: the word "grown" grows in pitch and dynamic level from G2 to D3 and from $m p$ to $f$; "ungrown" reverses the pattern in a palindrome of pitch and dynamics. "Young" and "old" are also a pair of opposing bookends, the former going from $\mathrm{C}$ to $\mathrm{D}, m p$ to $f$ and the latter from $\mathrm{D}$ down to $\mathrm{F} \#$ at $m f$ decrescendo to $p$.

The set of five adjectives - "strong, ample, fair, enduring, capable"forms a single musical phrase, starting low, rising to "enduring," then settling down again at "capable." There is an interesting contrast of words that rise in intonation in the middle (strong, ample, enduring) and those that only fall (fair, capable). Dynamics also shape the phrase, starting at $m f$, rising to $f f$, and falling on the last word to $m p$ and $p p$.

The word "rich" serves both as segue to the last phrase and as dramatic interjection. It uses the second-highest note in the fragment (G3) that rises in dynamics to $f f$ before falling off. The beginning of the last phrase, at "Perennial with the earth," quickly rises to the highest note in the poem: an $\mathrm{A} b 4$ at $f f$ that does not drop off in pitch or dynamic level. This sets up the declining pitch and dynamic level that characterizes the last phrase. 
The transcription shows the speaker's concern with elements of musical sound: pitch, duration, and dynamics. Of sound's defining categories, it is only timbre that the speaker ignores in his performance. The other three form a rich and coherent musical tapestry: angular elegance of phrasing, pitch reinforcement of accents (except where noted above), large melodic range from $\mathrm{E} 2$ to $\mathrm{A} b 4$ (total range of sixteen semitones), melodic angularity with frequent tritones, canny phrasing, dramatic use of rhythm and dynamics, and satisfying dynamic phrase shapes. The rhythms here are limited to a small number of durations that are remarkably consistent throughout and happen to fit easily in a tempo of 120 . This is not to suggest that the poem is metrical, only that a metrical structure accommodates the rhythms (but not the accents) found there.

The recording is a masterful performance, read with authority, drama, and remarkable musical consistency. By focusing on subtle distinctions of sound, the transcription reveals the musical-poetic qualities of the fragment. A number of distinctions emerge in the poetics that begin to define the music of vers libre - which (as T.S. Eliot pointed out) isn't new. Like Columbus in America, Whitman did not discover free verse; but he attracted attention to its existence.

It is worthwhile to recall conclusions Eliot drew on the same subject, beginning when he says, "Any line can be divided into feet and accents" and ending when he says:

And as for vers libre, we conclude that it is not defined by absence of pattern or absence of rhyme, for other verse is without these; that it is not defined by non-existence of metre, since even the worst verse can be scanned; and we conclude that the division between Conservative Verse and vers libre does not exist, for there is only good verse, bad verse, and chaos. ${ }^{8}$

One wonders if Eliot's ironic tone arises from the inability of prosody to explain the difference between "good verse, bad verse, and chaos." That situation has not changed: poets and critics still fly on instruments when it comes to free verse. They require unerring accuracy of intuitive radar, but can't get it because performances are musically indeterminate.

The purpose of focusing on a particular performance of a text is to move criticism out of the realm of scholastic exercise (the text as it might be read) onto the fringes of science (the text as it has been read). The purpose of introducing subtle musical distinctions, such as pitch, dynamics, duration, portamento (pitch shift), real time, phrasing, parallelisms, pitch and dynamic palindromes, etc.-instead of relying on metrical feet of a stumbling prosody - is to begin to get at what makes good good, bad bad, and chaos chaotic.

As we have seen from a close listening and transcription of the "America" recording, free verse is pulse-less. In other words, there are 
patterns, but not any underlying steady tempo markers. Metrical verse might also turn out to be pulse-less in actual practice (read out loud), in which case a more accurate description would be to say that free verse has no regularly recurring accent. Whitman's free verse contains patterns in the text that can be accentuated in a masterful reading, such as on this recording. Hopefully the approach to poetics introduced here begins to untangle the complex of meanings currently obscured inside the term "free verse" and reveals a little more of the genius that may be discovered in Whitman by an excellent vocal reading.

Santa Barbara, $C A$

\section{NOTES}

1 Larry Don Griffin, "Walt Whitman's Voice," Walt Whitman Quarterly Review 9 (Winter 1992), 125-133.

2 Ed Folsom, “The Whitman Recording," Walt Whitman Quarterly Review 9 (Spring 1992), 214-216.

3 Jim Hermanson, in "The Voice of the Poet?" (The Red Wheelbarrow, redhermwheelbarrow.blogspot.com/2011/03/voice-of-poet.html, March 27, 2011), offers a full summary and analysis of the history of, controversy surrounding, and authenticity of the wax-cylinder recording.

4 The recording is available on the Walt Whitman Archive (whitmanarchive.org).

5 I describe my new poetics methodology at http://www.tribd.com/new-poeticsmethodology.pdf

6 As Gay Wilson Allen said, "no book is more conspicuous in Walt Whitman's 'long foreground' than the King James Bible"; see A Reader's Guide to Walt Whitman (New York: Farrar, Straus \& Giroux, 1970), 24.

7 Actually, numerical count is $99.5 \%$ correlation of accent and pitch rise, found in this transcription of a Catherine Daly poem: jacketmagazine.com/40/r-daly-vauxhallrb-cooley.shtml.

8 T.S. Eliot, "Reflections on Vers Libre," in To Criticize the Critic (London: Faber \& Faber, 1978), 183-189. 